\title{
ASSESSING PROGRESS TOWARDS IMPACTS IN ENVIRONMENTAL PROGRAMMES USING THE FIELD REVIEW OF OUTCOMES TO IMPACTS METHODOLOGY
}

\section{David Todd and Rob Craig}

\section{Impacts in the context of environmental programmes and projects}

The GEF Evaluation Office impact evaluation programme's main objective was to evaluate the long-term results of interventions several years after GEF support had concluded - to assess the sustainability and replication of results and draw out lessons learned. An earlier GEF evaluation, The Role of Local Benefits in Global Environmental Programs ${ }^{3}$ had demonstrated that social means must be used in order to deliver environmental results. This is because human behaviour towards the environment is a critical factor in achieving sustainable natural resource management. Examples include biodiversity (the interactions between the local human population and natural resources), climate change (the role of domestic and industrial energy use), international waters (damage caused by overfishing, nutrient spill and pollution) and land degradation (the importance of changing land and water use practices in farming systems).

These insights on the importance of using social means to achieve environmental ends were combined with the use of cause and effect chains as a theoretical basis upon which to assess progress towards long-term objectives. The result was a specific fieldwork-based evaluative approach, known as the 'Review of Outcomes to Impacts'(ROtI). This was used to evaluate progress towards project impacts in a series of studies, one of which is described in detail here: The Seychelles Marine Ecosystem Management Project (SEYMEMP). ${ }^{4}$

\section{The elements of a Theory of Change for environmental interventions}

The Theory of Change for a project is the logical sequence of conditions and factors that are necessary to deliver its ultimate impact. A basic project Theory of Change starts with activities and develops through a means-ends hierarchy until 
finally reaching a project's impacts. Project Terminal Evaluations implicitly assess against a basic Theory of Change as far as outcomes, but do not usually go further in assessing the crucial last steps towards impact. The Review of Outcomes to Impacts assessment takes up where Terminal Evaluations leave off and focuses on developing and assessing a detailed Theory of Change between outcomes and impacts, referred to as outcomes-impacts pathways.

Key elements in the outcomes-impacts pathways are Intermediate States, impact drivers and assumptions; these are defined in Table 7.1 and illustrated in Figure 7.1. If project outcomes are assessed to be successfully delivered and the key elements of the Theory of Change between outcomes and impacts are in place, then it is reasonable to conclude that there is indirect evidence that the impact has been or will be achieved with time.

TABLE 7.1 Definitions of Theory of Change Elements in the Outcomes-Impacts Pathways

\begin{tabular}{ll}
\hline Theory of Change terms & Definition \\
\hline Outcomes & $\begin{array}{r}\text { Short- to medium-term behavioural or systemic effects result } \\
\text { from outputs designed to help achieve the project's impacts } \\
\text { (e.g. capacities developed). }\end{array}$ \\
Intermediate States & $\begin{array}{r}\text { The transitional conditions between a project's outcomes and } \\
\text { impacts that must be achieved in order to deliver the intended } \\
\text { impacts. } \\
\text { The significant factors that, if present, are expected to contribute } \\
\text { to the ultimate realization of project impacts and that are } \\
\text { within the ability of the project to influence. } \\
\text { The significant factors that, if present, are expected to contribute } \\
\text { to the ultimate realization of project impacts but that are } \\
\text { largely beyond the power of the project to influence or address. }\end{array}$ \\
Assumptions &
\end{tabular}

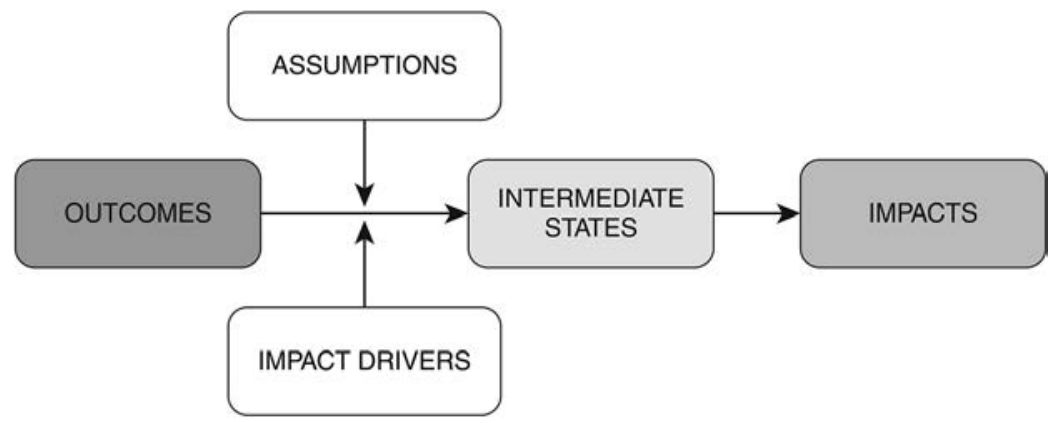

FIGURE 7.1 The Relationship between the Key Elements in a Project Theory of Change 


\section{The field Review of Outcomes to Impacts methodology}

One of the methods developed and practised by the GEF Independent Evaluation Office $^{5}$ to assess progress towards impacts of completed GEF-assisted activities is the 'field Review of Outcomes to Impacts'. ${ }^{6}$ This uses a combination of different information collection methods, as shown in Figure 7.2. It begins with a desk review, proceeds with consultations with key project stakeholders and concludes (when possible) with fact-finding at the project site or sites. Ideally, field investigation is followed by further consultation with key informants and additional desk research to confirm information and project documentation facts that were collected in the field.

During the assessment process, it is necessary to gradually develop an understanding of the status of the Intermediate States, impact drivers and assumptions through a combination of the steps shown in Figure 7.2. On this basis, the evaluator is able to draw conclusions and establish a set of qualitative and/or quantitative findings. Specifics of the key methodological steps are discussed in the following.

\section{Desk research}

As far as possible, all relevant documentation is consulted during the initial desk research step. This includes previous evaluation documents, the project outputs/ terminal reports and any subsequent reports relating to the sustainability or follow-up to the project. At a minimum, a thorough understanding of the project document and Terminal Evaluation is an essential foundation for undertaking the subsequent steps of a field Review of Outcomes to Impacts assessment. A useful output of the initial desk research step is a 'key issues checklist' that summarizes the key information that the assessment needs to focus on in order to validate and assess the project Theory of Change.

\section{Key informants}

The consultation with key informants provides an opportunity to obtain additional documents, either produced for or resulting from the project, that assist in cross-checking and validating the assessment. Consultations are conducted in the following order:

1. Officials: The consultation process should start with the officials involved in the project, for example, officials from participating government departments and representatives of project implementing agencies.

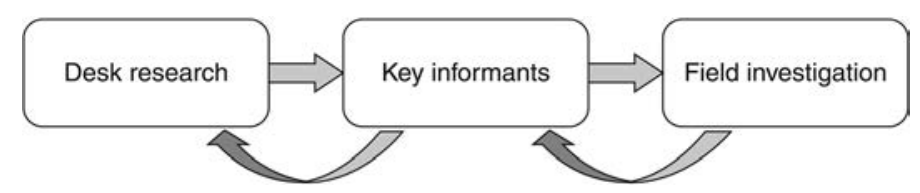

FIGURE 7.2 Steps in the Field-Based Review of Outcomes to Impacts Assessment Process 


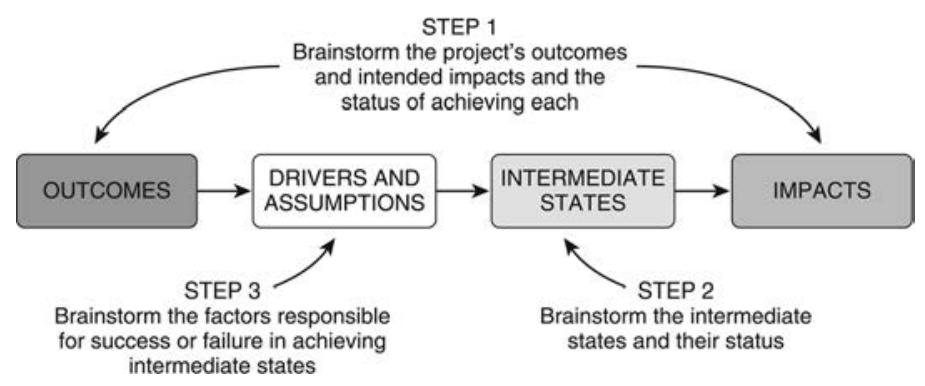

FIGURE 7.3 Steps in Conducting a Field Review of Outcomes to Impacts Analysis with Group or Individual Key Informants

2. Focus groups: The Review of Outcomes to Impacts field assessment exercise is ideally conducted as a group exercise with a cross-section of individuals that were responsible for the design and implementation of the specific project being assessed. In some cases, it is necessary to hold more than one focus group for a particular project depending on the logistics and the politics of bringing various individuals together. In other cases, it is not possible to convene focus groups; in these instances, it is necessary to discuss the relevant section of the Theory of Change with each individual or institution in turn.

3. Individual experts: After the focus group exercise, it is often necessary to follow up and cross-check findings with key individuals who were not able to attend the focus group meetings.

The basic order of activities to undertake during the Review of Outcomes to Impacts Exercise $^{7}$ with the focus group and individual experts is illustrated in Figure 7.3.

\section{Step 1: Validating project logic}

This is done by presenting the outcomes and impacts identified during the desk review stage and asking the focus group to validate and comment on them. Key questions to ask are

- What was the project ultimately trying to achieve (i.e. project impact)?

- What did the project actually achieve at completion (i.e. project outcomes)?

\section{Step 2: Assessing Intermediate States}

The focus group then identifies the Intermediate States and the results are compared with those from the desk review. Questions to ask in identifying and assessing the Intermediate States are

- What has already been achieved since project completion to contribute to impacts?

- What else needs to happen to deliver the intended impacts? 


\section{Step 3: Assessing the impact delivery process}

Once an understanding has been developed of the achievement or otherwise of the intermediate state, it is then possible to look at the factors that may have resulted in this situation by examining the presence or absence of the identified impact drivers and assumptions. The basic question to ask is

- What were the reasons for successes or failures in delivering the Intermediate States?

The Review of Outcomes to Impacts exercise with the focus groups (and to a lesser extent with individual experts) uses visualization techniques to present the elements of the Theory of Change and to facilitate a collective process of thinking.

The end result is the establishment of a stakeholder consensus on the outcomesimpacts Theory of Change model for the specific project, plus a more detailed understanding of the status of the project's outcomes-impacts pathways and the key underlying factors responsible for success or failure. Annex 1 shows the specific Theory of Change model developed by the focus group exercise for the Seychelles Marine Ecosystem Management Project (SEYMEMP).

\section{Field investigations}

The project Theory of Change models and the initial assessments given during the key informant focus groups and consultations are then cross-checked through field visits to former project sites and discussions with relevant beneficiary institutions and communities. This also provides a good opportunity to gather available field data to back up the overall assessment findings. These findings should then be further cross-checked with the key informants and available literature collected during the process.

\section{Reporting of the assessment findings}

The field Review of Outcomes to Impacts rating system provides a simple score that gives a summary indication of progress towards the project's expected impact (see Table 7.2). The rating system is applied at the different hierarchical levels of the Theory of Change - namely at the individual Theory of Change element level

TABLE 7.2 Field Review of Outcomes to Impacts Rating System

\begin{tabular}{ll}
\hline Rating & Description \\
\hline 0 & Not achieved \\
1 & Poorly achieved \\
2 & Partially achieved \\
3 & Fully achieved \\
\hline
\end{tabular}


(outcomes, Intermediate States, impact drivers and assumptions), at the overall strategy level and at the overall project level.

Below the rating, scores are elaborated with descriptions of the general interpretations implied from a theoretical and/or delivery perspective. These descriptions are provided as guidance for scoring; it is recognized that projects are extremely complicated and that evaluators need to use value judgements in order to score projects.

\section{Not achieved - (0)}

From a theoretical perspective, the Theory of Change aspect is not explicitly or implicitly identified by the project, and/or from a delivery perspective, very little progress has been made towards achieving the Theory of Change; the conditions are not in place for future progress.

\section{Poorly achieved - (1)}

From a theoretical perspective, there are no appropriate mechanisms set out to achieve the Theory of Change aspect after GEF funding ended, and/or from a delivery perspective, little progress has been made towards achieving the Theory of Change aspect; the conditions are in place for future progress.

\section{Partially achieved - (2)}

From a theoretical perspective, the Theory of Change aspect is explicitly recognized and the mechanisms set out to achieve it are appropriate but insufficient (e.g. there is no clear allocation of responsibilities for implementing the mechanisms after GEF funding ends). From a delivery perspective, moderate and continuing progress is being made towards achieving the Theory of Change aspect, although there is not yet a strong basis for the eventual delivery of the intended global environmental benefits.

\section{Fully achieved - (3)}

From a theoretical perspective, the Theory of Change aspect is explicitly recognized and appropriate and sufficient mechanisms to achieve it are apparent (e.g. specific allocation of responsibilities after GEF funding ended), and/or from a delivery perspective substantial progress has been made towards achieving the Theory of Change aspect and a strong basis is in place for eventual delivery of the intended Global Environment Benefits.

The reporting of the Review of Outcomes to Impacts assessment is initially done for each strategy, assessing the individual Theory of Change element level comprising the strategy (i.e. the outcomes, impact drivers, assumptions and Intermediate States). The assessment for the Intermediate States, by virtue of the means-ends logic of the Theory of Change model, is based both on a direct assessment of the 
intermediate state itself and on the individual assessments of the relevant outcomes, impact drivers and assumptions. This is necessarily an inexact measurement, based on the evaluator's considered judgement of the achievement of the intermediate state rather than on any definitive measure of achievement.

\section{Background: the Seychelles Marine Ecosystem Management Project}

The Seychelles Marine Ecosystem Project was a medium-sized GEF/World Bank project that was implemented from August 2000 to March 2004. The \$1.25 million project fell under the Coastal and Marine Biodiversity Operational Programme of the GEF Biodiversity Focal Area. GEF provided \$0.67 million in funding; the Government of the Seychelles co-financed the remainder. The stated goal of the project was the 'successful management of Seychelles' unique and threatened marine ecosystems in light of recent global and local changes in particular coral bleaching'. Its overall objective was 'identify, monitor, manage and rehabilitate remnant ecosystems by the removal of critical barriers including lack of skills, scientific understanding and conservation management knowledge and direction'.

At closure, the project was favourably rated by its Terminal Evaluation, with the delivery of project outcomes considered to have been 'satisfactory' and the probability of sustainability assessed to be 'likely'.

This chapter presents a Review of Outcomes to Impacts that seeks to answer whether the completed project has in fact contributed to achieving lasting and beneficial environmental impacts.

\section{The impacts towards which the SEYMEMP would contribute}

The starting point for the SEYMEMP Review of Outcomes to Impacts assessment was to identify the project's intended environmental impacts, which for GEF projects is the delivery of global environmental benefits. These are defined in the Review of Outcomes to Impacts manual as 'lasting improvements in the status of an aspect of the global environment that safeguards environmental functioning and integrity as well as benefiting human society'. The SEYMEMP project identified four key aspects of the marine environment that provided the justification for GEF support to this project and which formed the project's intended global environmental benefits. The benefits are lasting improvements in the status of hard coral reefs, reef fish assemblages, marine turtles and whale sharks (see Table 7.3).

It is important to have a clear understanding of the desired final impact of an intervention, since this provides the foundation for the development of an appropriate outcomes-impacts Theory of Change. To characterize the SEYMEMP global environmental benefits further, Table 7.3 provides the rationale for their selection according to their documented global significance, lists the key attributes essential for their long-term survival and identifies the main threats to attainment of the global environmental benefits. 
TABLE 7.3 Global Environmental Benefits (to Biodiversity) for the SEYMEMP Project

\begin{tabular}{|c|c|c|c|}
\hline $\begin{array}{l}\text { Global environmental } \\
\text { benefits }\end{array}$ & $\begin{array}{l}\text { Rationale for global } \\
\text { significance }\end{array}$ & Key attributes & Threats \\
\hline \multicolumn{4}{|l|}{$\begin{array}{l}\text { Lasting improvement } \\
\text { in the status of: }\end{array}$} \\
\hline $\begin{array}{l}\text { Hard coral reefs of } \\
\text { the Western Indian } \\
\text { Ocean }\end{array}$ & $\begin{array}{l}\text { The Seychelles coral reefs } \\
\text { are listed as an area } \\
\text { of 'rich to very rich } \\
\text { species diversity'. }{ }^{\star} \\
\text { In addition, the } \\
\text { comparative lack of } \\
\text { scientific information } \\
\text { of the coral reefs } \\
\text { makes it an important } \\
\text { area for international } \\
\text { scientific research in } \\
\text { future }\end{array}$ & $\begin{array}{l}\text { - } \text { Recruitment } \\
\text { - Water quality }\end{array}$ & $\begin{array}{l}\text { - Grazing } \\
\text { organisms, } \\
\text { e.g. Crown } \\
\text { ofThorns } \\
\text { starfish/urchins } \\
\text { - oral bleaching } \\
\text { and diseases } \\
\text { - Pollution } \\
\text { - Sedimentation/ } \\
\text { landslides } \\
\text { - Nautical } \\
\text { activities }\end{array}$ \\
\hline Reef fish assemblages & $\begin{array}{l}\text { Important indicators of } \\
\text { reef structure and } \\
\text { composition }\end{array}$ & 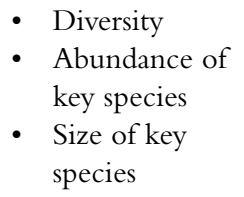 & $\begin{array}{l}\text { - Fisheries } \\
\text { - Pollution } \\
\text { - Sedimentation/ } \\
\text { landslides }\end{array}$ \\
\hline Whale sharks & $\begin{array}{l}\text { Listed on the Convention } \\
\text { on International Trade } \\
\text { in Endangered Species } \\
\text { Appendix II, as data } \\
\text { deficient by the } \\
\text { International Union } \\
\text { for the Conservation } \\
\text { of Nature, and in } \\
\text { Annex } 11 \text { of the } \\
\text { Convention on } \\
\text { Migratory Species }\end{array}$ & $\begin{array}{l}\text { - } \text { Numbers } \\
\text { - Reproduction } \\
\text { rates } \\
\text { - Sex ratios }\end{array}$ & 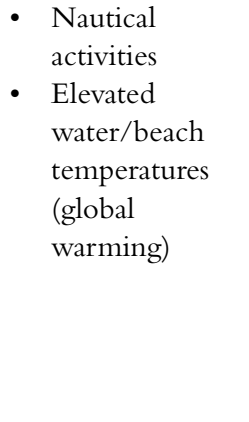 \\
\hline Marine turtles & $\begin{array}{l}\text { One of the five largest } \\
\text { remaining global } \\
\text { populations of } \\
\text { critically endangered } \\
\text { hawksbill turtles } \\
\text { (Eretmochelys } \\
\text { imbricata) and a } \\
\text { significant population } \\
\text { of endangered green } \\
\text { turtles (Chelonia } \\
\text { mydas) }\end{array}$ & $\begin{array}{l}\text { - Availability of } \\
\text { forage (coral } \\
\text { reef, sponges } \\
\text { and seagrass) } \\
\text { - } \text { Breeding sites } \\
\text { - } \text { Reproduction } \\
\text { rates } \\
\text { - Sex ratios }\end{array}$ & \\
\hline
\end{tabular}




\section{Outlining the outcomes-impacts Theory of Change for SEYMEMP}

The development of the SEYMEMP outcomes-impacts Theory of Change was based on a review of project documentation and discussions with key informants. Principal consultations with key informants were conducted as a focus group exercise using visualization techniques (as explained earlier and in detail in the GEF Review of Outcomes to Impacts Manual). ${ }^{8}$ The resulting overall project outcomesimpacts Theory of Change is presented in Table 7.4 and in the chapter Annex 1.The Theory of Change sets out what was intended to occur after project completion in order to eventually achieve the intended project impacts. In combination, the three Intermediate States would deliver direct actions to address threats to global environmental benefits (Intermediate State 1), an effective Marine Protected Area $(\mathrm{MPA})^{9}$ system to protect key marine sites (Intermediate State 2) and an enabling policy environment to ensure national and regional compliance and cooperation (Intermediate State 3). Together, the review considered these three states to be sufficient to achieve the intended impact.

\section{Evaluating progress against the Theory of Change}

According to the Theory of Change, achieving the three Intermediate States is necessary (although not necessarily sufficient) in order to achieve the intended impact. Therefore, the Review of Outcomes to Impacts assessed, in detail, the progress that was made since project completion along each of the cause and effect pathways from the four outcomes (already assessed in the project Terminal Evaluation) towards the three Intermediate States. However, in order to keep this chapter to a reasonable length, only one of the pathways (towards Intermediate State 3) is examined in detail. In the original review, ${ }^{10}$ all pathways were comprehensively reviewed to provide the evidence necessary to draw conclusions on progress towards impacts.

\section{Assessment of progress towards Intermediate State 3: implementation and mainstreaming of enabling marine policies at national and regional levels}

\section{Theory of Change overview}

The third intermediate state, 'implementation and mainstreaming of enabling marine policies at national and regional levels', was considered necessary to ensure that support and commitment for marine protection is maintained and scaled up through the formulation and enactment of enabling policies and laws. These would provide incentives and support mechanisms for marine ecosystem users (e.g. fisheries and tourism sectors) to comply, cooperate and become active partners in marine conservation. This intermediate state includes the neighbouring countries in the Indian Ocean in order to seek regional cooperation in protecting the greater ecosystem on which the Seychelles marine environment depends. 
TABLE 7.4 The SEYMEMP Outcomes-Impacts Theory of Change

Outcomes Impact drivers \& assumptions

What was the situation at the end of the What key factors were responsible for delivery (or project? non-delivery) of the Intermediate States?

Outcome 1: Seychelles marine ecosystems Impact driver: Research and monitoring and their values are better understood methodology integrated into ongoing initiatives and institutions

Impact driver: Research and monitoring capacity built in Seychellois institutions responsible for marine protection

Outcome 2: Coping mechanisms that directly address marine ecosystem degradation introduced
Impact driver: Coping mechanisms integrated and funded by existing structures
What was the project ultimately aiming to achieve?

the project ended, or still needs to happen, to achieve impacts?

Intermediate state: Coping Reduced human and mechanisms addressing major natural threats to threats to marine ecosystems are rolled out nationally Seychelles' fragile marine ecosystem habitats; fauna

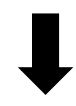

Enhanced conservation status of four marine global environmental benefits 
Outcome 3: Integrated marine protected Impact driver:Accountability and transparency in area system operationalized

Outcome 4: Broad stakeholder involvement and cooperation in the implementation of regional marine conservation programmes

Assumption: Government/Department of the

\section{decision-making}

Impact driver: marine protected area network is adequate to protect key ecosystem functioning

Impact driver: Financial sustainability of marine protected area network is established Environment has a clear vision of what it wants from plan and takes leadership role

Assumption:There is sufficient buy-in and common ground between stakeholders

Impact driver: Policies and Regulations established, Intermediate state:

$$
\text { understood and enforced }
$$

Impact driver:There are sufficient incentives for marine users to participate in programmes

Assumption: Political leadership is committed to prioritizing marine issues
Intermediate state: marine protected area network is being managed effectively to achieve conservation goals
Implementation and

mainstreaming of enabling marine policies at the national and regional levels 


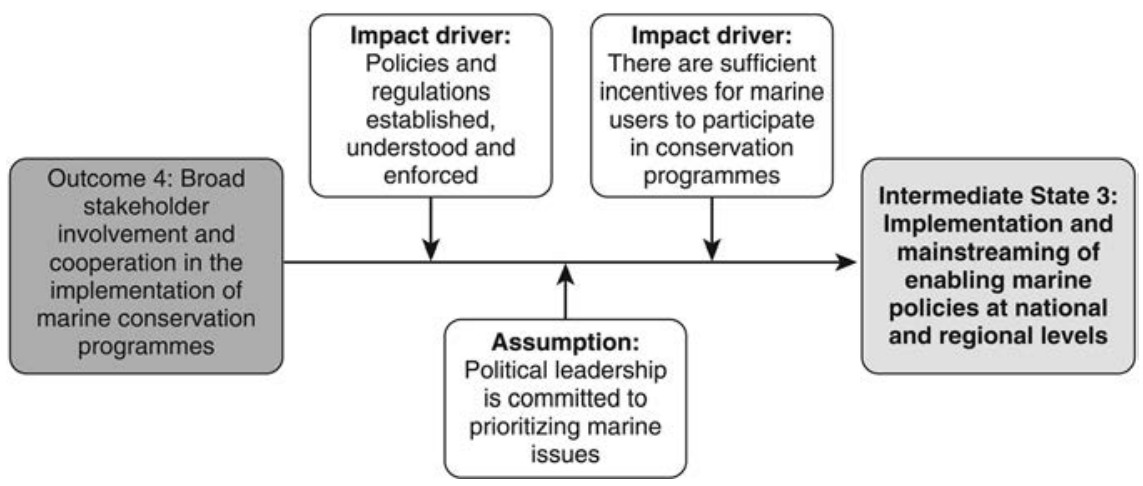

FIGURE 7.4 Theory of Change for Intermediate State 3

The project outcome that leads towards Intermediate State 3 is Outcome 4 (see Figure 7.4). This outcome focused on public education about the marine environment and on obtaining broad stakeholder inputs through institutional involvement and partnerships. Such partnerships included links with other regional marine conservation initiatives.

In order for the intermediate state to be achieved, the review identified two impact drivers and one external assumption, as shown in Figure 7.4. The first, 'policies and regulations established, understood and enforced', is critical to achieving the intermediate state, because clear rules and effective enforcement of regulations protecting the marine environment are the foundations for obtaining broad compliance from marine users for ensuring conservation. The second impact driver, 'there are sufficient incentives for marine users to participate in conservation programmes', seeks to complement law enforcement through education and tangible incentives to encourage marine users to proactively conserve the ecosystem. The external assumption, 'political leadership is committed to prioritizing marine issues', is critical to realizing the enabling policies and incentive schemes of the impact drivers.

The next section assesses the extent to which this element of the Theory of Change has been realized by examining the achievement of its components, starting with the outcomes and finishing with the intermediate state 3 . Table 7.5 provides a summary of this analysis.

\section{Theory of Change assessment}

\section{Outcomes}

The review agreed with the Terminal Evaluation that good progress was made in delivering the project's fourth outcome. The project successfully delivered awareness-raising activities, particularly through using local media and workshops to educate coral reef users (e.g. boat handlers, divers) and encouraging public participation 
TABLE 7.5 Outcomes-Impacts Assessment Findings for Intermediate State 3

\begin{tabular}{|c|c|c|}
\hline Theory of Change component & Qualitative Assessment & Rating \\
\hline $\begin{array}{l}\text { Outcome \#4: Broad } \\
\text { stakeholder } \\
\text { involvement and } \\
\text { support }\end{array}$ & $\begin{array}{l}\text { Good level of public awareness-raising activities } \\
\text { (workshops, local media, and publicity) } \\
\text { In addition to the project executing agencies } \\
\text { (Ministry of Environment, Marine } \\
\text { Conservation Society of Seychelles and Marine } \\
\text { Parks Authority), the project also involved the } \\
\text { Ministry of Land Use and Habitat, Seychelles } \\
\text { Fishing Authority and the Seychelles Islands } \\
\text { Foundation to encourage wider stakeholder } \\
\text { participation and build local capacities } \\
\text { Limited evidence that the above partnership } \\
\text { led to significant local capacity building } \\
\text { and inadequate links made with regional } \\
\text { initiatives (e.g. integrated coastal area } \\
\text { management process) }\end{array}$ & $\begin{array}{l}2 \text { (partially } \\
\text { achieved) }\end{array}$ \\
\hline $\begin{array}{l}\text { Impact Driver: Policies } \\
\text { and regulations } \\
\text { established, } \\
\text { understood and } \\
\text { enforced }\end{array}$ & $\begin{array}{l}\text { Based on the SEYMEMP research findings, the } \\
\text { government declared the whale shark as a } \\
\text { protected species under the Wild Animals and } \\
\text { Birds Protection Act (S.I. } 1 \text { of 2003) and the } \\
\text { whale shark programme is now a national } \\
\text { programme of action } \\
\text { The Government of the Seychelles endorsed the } \\
\text { RAMSAR Convention in 2005, along with } \\
\text { the enactment of the Wetlands Policy, which } \\
\text { provides clear regulations and a mandate to } \\
\text { the Wetlands Unit. The unit has successfully } \\
\text { policed illegal activities (dumping/ } \\
\text { reclamation) and ensured that major new } \\
\text { developments undertake environmental } \\
\text { impact assessments and comply with } \\
\text { guidelines. However, capacity in the unit is } \\
\text { not yet sufficient to enforce guidelines at the } \\
\text { household level }\end{array}$ & $\begin{array}{l}2 \text { (partially } \\
\text { achieved) }\end{array}$ \\
\hline $\begin{array}{l}\text { Impact Driver: There } \\
\text { are sufficient } \\
\text { incentives for marine } \\
\text { users to participate } \\
\text { in conservation } \\
\text { programmes }\end{array}$ & $\begin{array}{l}\text { Limited progress has been made in getting the } \\
\text { tourism or fishing industry to adopt mooring } \\
\text { installations and to support other initiatives } \\
\text { to reduce marine degradation. However, } \\
\text { the new UNDP/GEF Mainstreaming } \\
\text { Biodiversity Management into Production } \\
\text { Sector Activities should address this issue. } \\
\text { Through education awareness, the Wetlands Unit } \\
\text { has had success in getting schools and hotels } \\
\text { to look after their wetlands (e.g. establishment } \\
\text { of the Hotel Babarons' wetland boardwalk), } \\
\text { although enforcement is still the most } \\
\text { effective tool }\end{array}$ & $\begin{array}{l}1 \text { (poorly } \\
\text { achieved) }\end{array}$ \\
\hline
\end{tabular}


TABLE 7.5 (Continued)

\begin{tabular}{|c|c|c|}
\hline Theory of Change component & Qualitative Assessment & Rating \\
\hline $\begin{array}{l}\text { Assumption: Political } \\
\text { leadership is } \\
\text { committed to } \\
\text { prioritizing marine } \\
\text { issues }\end{array}$ & $\begin{array}{l}\text { The government is committed to the } \\
\text { marine environment, but lacks financial } \\
\text { resources, especially since the tightening } \\
\text { of government spending under the new } \\
\text { International Monetary Fund-supported } \\
\text { economic reform programme and the } \\
\text { reduction of international donor support for } \\
\text { the environment coming to the Seychelles } \\
\text { The government has not taken the critical } \\
\text { leadership role needed to overcome the } \\
\text { impasse in agreeing to and implementing } \\
\text { an integrated marine protected area system } \\
\text { plan with devolved responsibility for } \\
\text { implementation }\end{array}$ & $\begin{array}{l}1 \text { (poorly } \\
\text { achieved) }\end{array}$ \\
\hline $\begin{array}{l}\text { Intermediate State \#3: } \\
\text { Implementation } \\
\text { and mainstreaming } \\
\text { of enabling marine } \\
\text { policies at national } \\
\text { and regional levels }\end{array}$ & $\begin{array}{l}\text { Awareness is certainly in place, and some policies } \\
\text { are in place at the national and regional levels. } \\
\text { However, there is a need for policies and } \\
\text { actions to protect the behavioural aspects of } \\
\text { marine life, e.g. migratory routes, corridors } \\
\text { and spawning areas, which are not covered } \\
\text { under the current marine protected area } \\
\text { system } \\
\text { New initiatives, such as the European } \\
\text { Union-funded Regional Programme } \\
\text { for the Sustainable Management of the } \\
\text { Coastal Zones of the Indian Ocean } \\
\text { Countries and the new set of UNDP/GEF } \\
\text { projects are focusing on mainstreaming } \\
\text { existing policies }\end{array}$ & $\begin{array}{l}1 \text { (poorly } \\
\quad \text { achieved) }\end{array}$ \\
\hline
\end{tabular}

in monitoring of turtles, whale sharks and aspects of the coral reef programme. The project also involved the Ministry of Land Use and Habitat, the Seychelles Fishing Authority and the Seychelles Islands Foundation in order to encourage wider stakeholder participation and build local capacities. However, an over-reliance on overseas consultants (coupled with limitations on their time) meant that local capacity-building activities were not given the attention or time needed to make a difference. In addition, intended partnerships with broader initiatives (such as the integrated coastal area management project) were not realized. The partial delivery of this outcome provided some basis for the eventual achievement of Intermediate State NumberThree, depending on the status of the impact drivers and assumptions. 


\section{Impact drivers/external assumptions}

The review found evidence that the first impact driver, 'policies and regulations established, understood and enforced', was partially delivered. The project made effective contributions towards strengthening environmental policy and regulations in the Seychelles. A major accomplishment was towards modifying the Wild Animal and Birds Protection Act to include whale sharks (S.I. 1 of 2003). This government decision was based on the project's whale shark programme research findings and has since become a national programme of action. Another significant piece of enabling policy to which the project contributed concerned wetlands management, with the government's endorsement of the 1971 Convention on Wetlands of International Importance (the RAMSAR Convention) and its enactment of the Wetlands Policy in 2005. These have provided the Wetlands Unit with the regulations and mandate to police against illegal activities (such as dumping and reclamation) and to ensure that major new developments comply with wetlands guidelines. This should have the long-term effect of reducing contamination and damage to the marine environment and coral reefs. However, this impact driver was not considered to be fully delivered because the regulations approved do yet not offer full coral reef protection and the capacity to enforce the existing and new regulations remains limited.

The review found that the second driver, 'there are sufficient incentives for marine users to participate in conservation programmes', has been poorly realized. The lack of progress since project closure to create incentives for marine users (such as tour operators and the fisheries industry) to participate in conservation programmes can, in part, be attributed to the reduction in available environmental funding. This was due to the decrease in international donors supporting the Seychelles and the recent implementation of the International Monetary Fundsupported economic reform programme. The lack of effective cooperation between government and non-governmental organizations and the lack of capacity retained in government institutions also played a role.

However, newly funded initiatives have recently been launched that have the potential to overcome these barriers to realizing this impact driver. In particular, there are new United Nations Development Programme (UNDP)/GEF projects: The Mainstreaming Biodiversity Management into Production Sector Activities project, which will focus on the fisheries and tourism sector, and the Capacity Development for Sustainable Land Management project, which will build on the SEYMEMP work on wetlands management. There is also a UNDP/ GEF marine and terrestrial protected area project in the proposal development stage. In addition to GEF projects, there is a European Union-funded Regional Programme for the Sustainable Management of the Coastal Zones of the Indian Ocean Countries that is in its early stages of implementation, which should help to encourage broader community participation and links with other countries in the western Indian Ocean. 
The review assessed that the assumption, 'political leadership is committed to prioritizing marine issues' has been poorly realized. Although the government is, in principle, committed to the marine environment, it lacks the financial and human resources to fully realize its leadership role.

\section{Overview of progress towards Intermediate State 3}

The Review of Outcomes to Impacts concluded that this Intermediate State remains at an early stage of delivery. Most notably, progress has been made in promoting enabling policies and there is greater awareness concerning the marine global environmental benefits. In addition, new initiatives, such as the European Union-funded Regional Programme for the Sustainable Management of the Coastal Zones of the Indian Ocean Countries and the new set of UNDP/GEF projects are providing opportunities for mainstreaming many of the issues raised by the SEYMEMP project. However, the current lack of government leadership, intersectoral cooperation and participation of marine users has meant that this intermediate state has not yet been significantly delivered. Policies and other sectors' involvement are still needed to protect the behavioural aspects of marine global environmental benefits (e.g. migratory routes, corridors and spawning areas), which are not covered under the current marine protected area system or by regulations. In conclusion, the overall assessment for the delivery of Intermediate State Number Three is poorly achieved.

\section{Assessment of progress towards Intermediate State 1: coping mechanisms addressing major threats to marine ecosystems are rolled out nationally ${ }^{11}$}

\section{Theory of Change overview}

The review considered the first intermediate state, 'coping mechanisms addressing major threats to marine ecosystems are rolled out nationally', to be an essential (necessary) ingredient to delivering the intended impact: improved conservation status of the Seychelles coral reef ecosystem and globally endangered marine species. The coping mechanisms are a series of direct actions that provide long-term protection against human-induced threats (e.g. coral damage by boats or pollution entering the ecosystem), as well as protection against detrimental natural events (e.g. the coral bleaching events of 1998 that destroyed a large percentage of the corals in the Seychelles islands). To minimize the threats to the ecosystem, it is essential that there is sufficient sustainable financing and capacity within local institutions (government, non-governmental organizations and the private sector) to enable appropriate responses to emerging threats to be launched as and when necessary.

The study team identified Outcomes 1 and 2 as important for delivering this intermediate state (see Figure 7.5). The research and monitoring activities undertaken to deliver Outcome 1 are essential for testing, adapting and scaling up the coping mechanisms piloted under Outcome 2. 


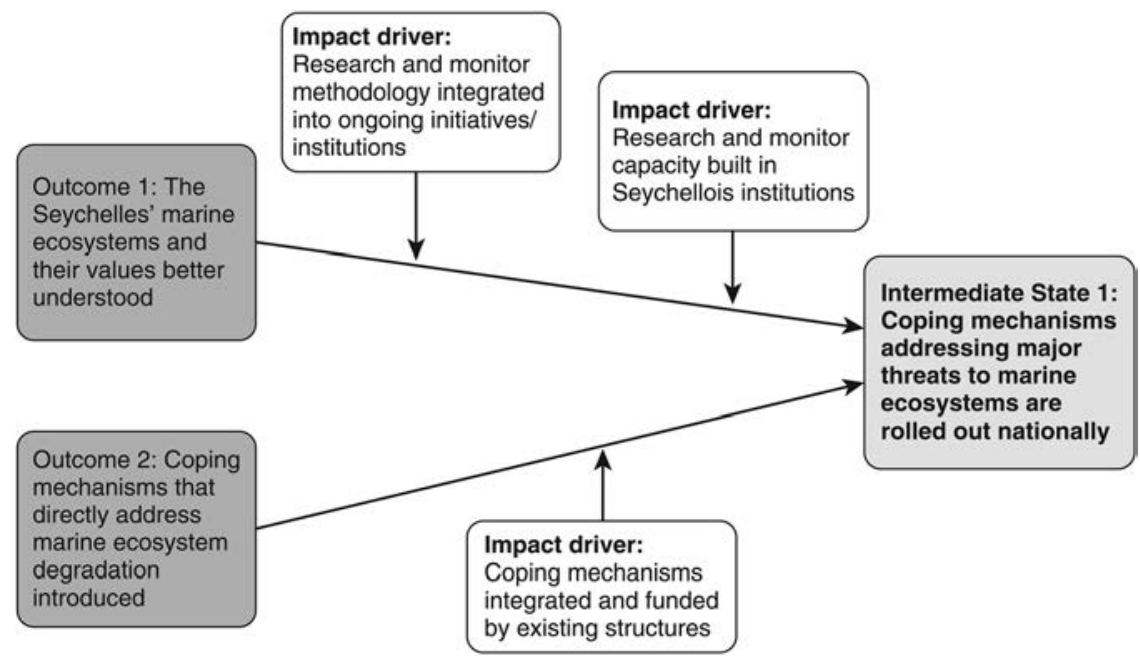

FIGURE 7.5 Theory of Change for Intermediate State 1

The review identified three impact drivers necessary to bridge the gap between the project outcomes and the delivery of the intermediate state (see Figure 7.5). The first, 'research and monitoring methodology integrated into ongoing initiatives and institutions', is necessary to ensure that the research and monitoring findings and methodologies of the project are utilized by all marine research bodies active in the Seychelles. This would help ensure the necessary continuity to build understanding of the ecosystem and to better inform the development and application of coping mechanisms. The second impact driver, 'research and monitor capacity built in Seychellois institutions', is related to the first driver but specifically relates to marine institutions' capacities to implement the research and monitoring programmes initiated under Outcome 1 (e.g. sufficiently trained personnel). The final driver, 'coping mechanisms integrated and funded by existing structures', is regarded as fundamental for the successfully piloted coping mechanisms of Outcome 2 to be more broadly applied across the marine ecosystem. The review did not consider there to be any major external assumptions underpinning the achievement of the intermediate state.

\section{Overview of progress towards achieving Intermediate State 1}

The review found evidence that the intermediate state had begun to be delivered. In particular, the project-initiated research findings have led to important decisions regarding marine protection at the national level (such as controls on fisheries in sensitive marine areas) that are expected to deliver a lasting improvement to the conservation status of the overall Seychelles marine ecosystems. In addition, the formation of the Seychelles Centre for Marine Research and TechnologyMarine Parks Authority (SCMRT-MPA) following project closure provides a better 
institutional mechanism for linking marine research with management actions. However, to date, the limited research and monitoring capacity built into government institutions with responsibility for the Seychelles marine ecosystem and the lack of funding mechanisms for rolling out marine protection activities have formed a barrier to fully delivering the scaling up of coping mechanisms needed to achieve the intended impact. In summary, the overall assessment for the delivery of Intermediate State 1 is partially achieved.

\section{Assessment of progress towards Intermediate State 2: marine protected area network is being managed effectively to achieve conservation goals}

\section{Theory of Change overview}

The intermediate state, 'Marine Protected Area (MPA) network is being managed effectively to achieve conservation goals', was the second key ingredient necessary to contribute towards delivering the intended project impact. As the understanding of the Seychelles marine ecosystem improves, it is becoming apparent that existing marine protected area coverage is inappropriate and insufficient to conserve all the ecologically important and sensitive areas, both in terms of global environmental benefits and the ecosystem functions and processes supporting them. ${ }^{12}$ An effectively managed Seychellois MPA network would adapt its coverage where appropriate and feasible and would ensure that each MPA is managed as part of an integrated system rather than as an individual, isolated entity. When such an integrated MPA system is in place, the review considers that conservation goals and impacts will have been achieved. This intermediate state is focused on enhancing the conservation status of the threatened marine species.

The study team identified Outcome 3 as critical for delivering this intermediate state (see Figure 7.6). Outcome 3 sought to lay the foundation necessary to run an integrated MPA network, in particular by planning and agreeing to the long-term arrangements and institutional modalities for implementing such a network.

The review identified two impact drivers and two external assumptions as being necessary to bridge the gap between the delivery of Outcome 3 and the achievement of Intermediate State 2 (see Figure 7.6). The first impact driver,'MPA network is adequate to protect key ecosystem functions and processes', is regarded as an important consideration that should be asked periodically of all protected area systems, based on current scientific understanding, to ensure that they are adequately protecting the ecosystem processes that sustain the associated impacts (e.g. global environmental benefits). The second driver, 'financial sustainability of MPA network is established', underpins the ability to manage, enforce and coordinate activities within and between MPAs and is therefore fundamental to the successful delivery of this intermediate state.

Regarding the external assumptions, the first, 'government has a clear vision for the MPA network and takes the leadership role for its development', is considered crucial for achieving the intermediate state, because government is the only stakeholder with the mandate and authority to expand or alter protected area system coverage and 


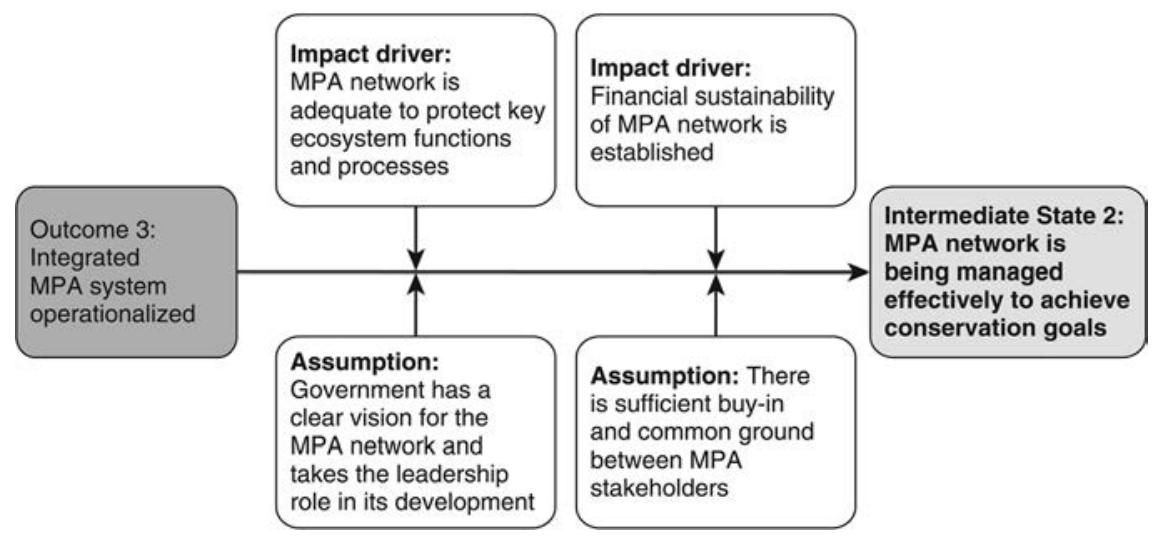

FIGURE 7.6 Theory of Change for Intermediate State 2

adjust, where necessary, the associated management regimes. The second assumption, that 'there is sufficient buy-in and common ground between MPA stakeholders', is also considered critical. This is because diverse actors (e.g. parastatal bodies, non-governmental organizations and the private sector) are involved in effectively managing an MPA network, and without transparency, accountability and willingness to pool resources together it is unlikely that such a network will be effectively managed.

Overall, the review found limited evidence to show that the second intermediate state had been delivered. Due to the lack of an agreed strategy for developing a more integrated MPA network, no substantive progress has been made to improve the coverage of MPAs to capture the critical coral refugia and other representative ecosystem components identified by the project as being outside of the existing system. Although informal collaboration between the Seychelles Centre for Marine Research and Technology-Marine Parks Authority and the Seychelles Fisheries Authority over the management of spawning grounds has been initiated, no significant progress has been made to improve management efficiency between organizations dealing with Marine Protected Areas. In conclusion, the overall assessment for the delivery of Intermediate State Number Two is that it has been poorly achieved.

\section{Current status of progress towards the intended impacts}

The Review of Outcomes to Impacts did not undertake a direct assessment of the status of the intended global environmental benefits that formed the intervention's intended impacts. However, project documentation was reviewed to collate existing information about the global environmental benefits and their conservation status. Table 7.6 provides a summary of the information that the review acquired.

The research reports emerging from the SEYMEMP project assessed the ecological status of the coral reef and reef fish assemblages following the 1998 coral bleaching event, which generally showed slow but steady recovery, and monitored the ecological status of whale shark and turtles, which, although providing a good 
TABLE 7.6 Available Information on Global Environmental Benefit Status

\begin{tabular}{|c|c|c|}
\hline \multirow[b]{2}{*}{ Global environmental benefit } & \multicolumn{2}{|l|}{ Change in status } \\
\hline & At project end (2004) & Since 2004 \\
\hline $\begin{array}{l}\text { Coral Reef of the } \\
\text { Western Indian Ocean }\end{array}$ & $\begin{array}{l}\text { Hard corals had shown a slow but } \\
\text { accelerating recovery. There was no } \\
\text { overall loss of coral biodiversity, but } \\
\text { the corals are still very vulnerable to } \\
\text { ecological disturbances. }\end{array}$ & $\begin{array}{l}\text { No information } \\
\text { available }\end{array}$ \\
\hline Reef fish assemblages & $\begin{array}{l}\text { Project recorded significant increases } \\
\text { in the abundance of some twenty } \\
\text { fish categories between } 2002 \text { and } \\
2003 \text {, which seems to relate to } \\
\text { increased recruitment resulting from } \\
\text { favourable conditions (which may } \\
\text { not be sustained in the future). }\end{array}$ & $\begin{array}{l}\text { No information } \\
\text { available and } \\
\text { no figures on } \\
\text { sustainable off-take } \\
\text { of commercial reef } \\
\text { fish }\end{array}$ \\
\hline Whale sharks & $\begin{array}{l}\text { Exploratory research revealed that } \\
\text { whale sharks around the Seychelles } \\
\text { Granitic island population consist } \\
\text { almost entirely of male juveniles, } \\
\text { which migrate in when plankton is } \\
\text { available. }\end{array}$ & $\begin{array}{l}\text { No data seen by study } \\
\text { team, although } \\
\text { the Marine } \\
\text { Conservation } \\
\text { Society of } \\
\text { Seychelles is } \\
\text { still conducting } \\
\text { research }\end{array}$ \\
\hline Marine turtles & $\begin{array}{l}\text { Hawksbill: between the early } 1980 \mathrm{~s} \\
\text { and } 2003 \text {, estimated numbers have } \\
\text { declined by approximately } 25 \% \text {. But } \\
\text { at unprotected sites the decline has } \\
\text { been approximately } 60 \% \text {. Population } \\
\text { in early } 2000 \text { s was estimated at } 625 \text {. } \\
\text { Green turtles: numbers of nesting turtles } \\
\text { in the inner islands have remained } \\
\text { less than } 50 \text { animals from the early } \\
\text { 1980s to } 2002-2003 \text {. Increases in } \\
\text { population are only evident on four } \\
\text { privately managed islands of Cousin } \\
\text { (571\%), Aride (167\%), and Cousine } \\
\text { and Bird islands, for which no } \\
\text { specific estimates could be obtained. }\end{array}$ & $\begin{array}{l}\text { No data seen by } \\
\text { the study team, } \\
\text { although Turtle } \\
\text { Action Group } \\
\text { and other non- } \\
\text { governmental } \\
\text { organizations are } \\
\text { still conducting } \\
\text { monitoring and } \\
\text { research }\end{array}$ \\
\hline
\end{tabular}

baseline, did not provide any clear trends in status. The review was unable to obtain information on the ecological status of the global environmental benefits following project completion. Although certain non-governmental organizations are continuing to gather data, particularly regarding marine turtles and whale sharks, the analysis of these data (if collected) are not publicly available.

Regarding the status of threats to the global environmental benefits, the review did not undertake threat assessments. However, discussions with stakeholders 
indicated that the threats are likely to be increasing, with more hotels in and around MPAs in the inner islands. Although the outer islands used to be protected due to their isolation, recent developments in the region (e.g. increased reach of fisheries due to larger vessels with greater cruising ranges and the market for more remote nature-based tourism activities) have made these threats more likely.

A direct assessment of global environmental benefits would require a separate study to compile and assess the monitoring data being collected by various institutions, which was beyond the scope of a Review of Outcomes to Impacts. In the case of the Seychelles, the review felt that the Seychelles Centre for Marine Research and Technology-Marine Parks Authority would be well positioned to coordinate an annual assessment on the status of these and other potential global environmental benefits, which could feed into the further development/expansion of the integrated Marine Protected Areas network.

\section{Overall conclusions on progress towards impacts of the SEYMEMP}

The study team used the Theory of Change methodology to assess that to date, only poor to partial success has been achieved in delivering the intended global environmental benefits/impacts (see Figure 7.7). Based on the continued monitoring and protection activities of individual institutions (e.g. the Marine Conservation Society of Seychelles, Whale Shark Programme and the Turtle Action Group monitoring), and the enacting of more enabling policies, the review team assessed that the conservation status of whale sharks and turtles has remained stable or improved following project closure. However, the review did not find any evidence of an improvement in the conservation status of the coral reef and reef fish assemblages, as the overall marine protected area system has not yet been expanded to protect the emerging patterns of hard coral distribution and abundance. Furthermore, the project's coral protection measures have not been scaled up (e.g. mooring installations and maintenance), and in some cases, these activities have been discontinued (e.g. programme to remove coral grazing organisms).

The Review of Outcomes to Impacts assessment concluded that the limited progress in delivering impacts has been mainly the result of the lack of institutional capacity, leadership and collaboration in further developing and integrating the management of the Seychelles' marine protected area network.

The lack of national-level coordination and leadership capacity for marine research and monitoring seems to have partly resulted from the over-reliance of the project on external consultants to undertake key aspects of the project. As identified in the project brief and Terminal Evaluation report, the national Marine Unit was envisioned to be the focus for developing research capacity and leadership in improving marine protected area management. But the unit relied heavily on a project adviser and other institutions and consultants to conduct the research and did not develop sufficient internal capacity and long-term funding sources during the project. As a result, the future of the marine unit appears to be unsustainable and a different institutional arrangement is needed to provide leadership. 


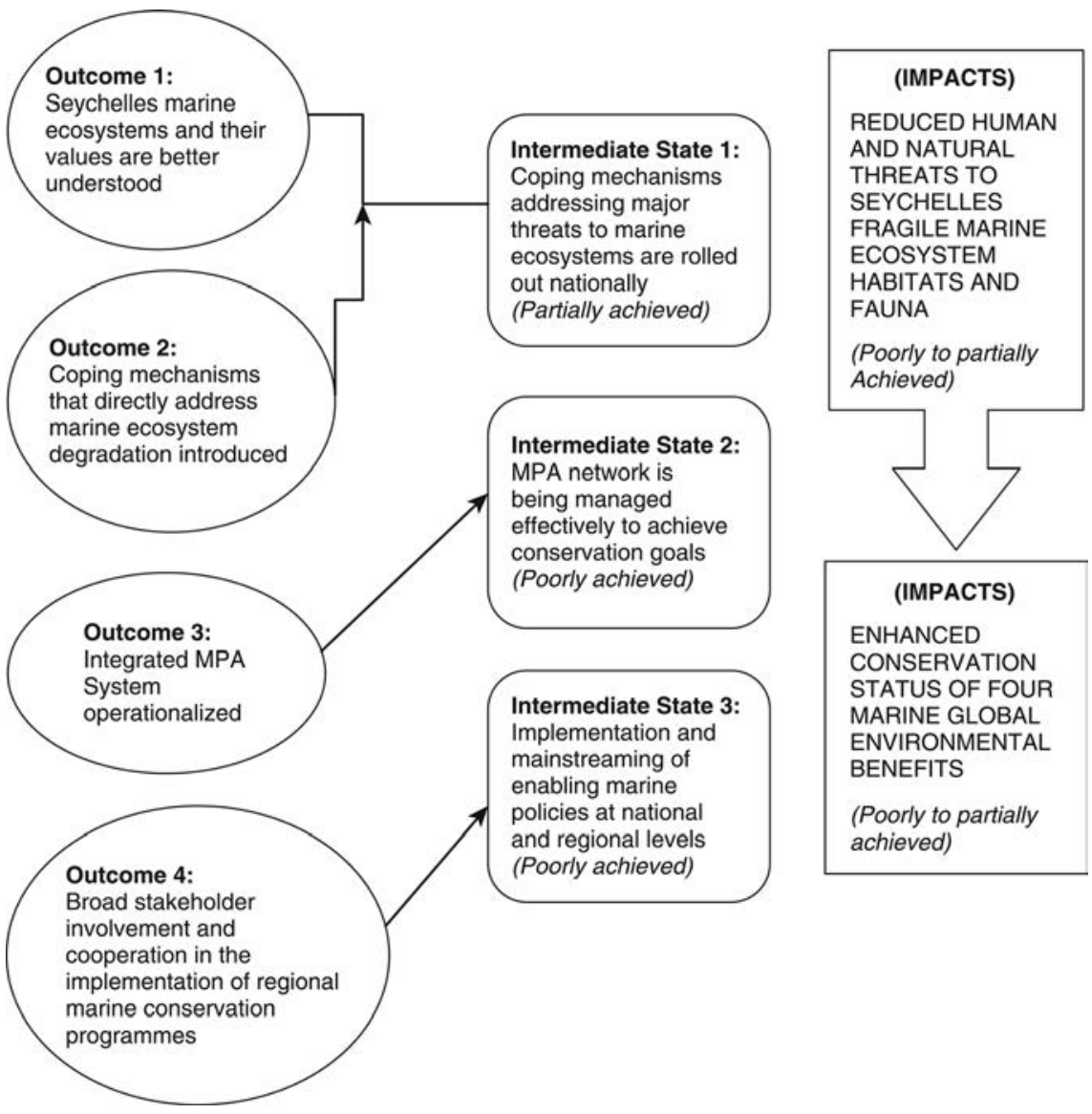

FIGURE 7.7 Overall Review of Outcomes to Impacts Assessment of SEYMEMP Progress towards Impacts

The diverse institutions involved in marine conservation require a clear framework for coordination of research and management and the adoption of a systematic approach to the further expansion of a more representative and integrated marine protected area network. The failure to date to implement the project's Integrated MPA System Plan and the continued lack of an agreed plan or framework for cooperation has meant that the status of the protected area network has remained little changed since project closure, with no new protected areas gazetted and management effectiveness basically unchanged.

However, the review concluded that the intended impacts could still be achieved if this barrier of lack of institutional capacity, leadership and cooperation can be overcome. A development in this direction is the amalgamation of the Seychelles Centre for Marine Research and Technology with the Marine Park Authority to form the SCMRT-MPA in 2003. The SCMRT-MPA provides an appropriate institution to take over the role envisaged for the Marine Unit in coordinating marine 
research, feeding it into the Marine Protected Area management decision-making and championing the revival of the MPA System Plan or an equivalent for developing an integrated MPA network. SCMRT-MPA has already made progress on the research side, but has yet to take on the role of leading the process to develop a more integrated and expanded MPA system.

\section{Overall conclusions on assessing progress towards impacts in environmental programmes using the field Review of Outcomes to Impacts (ROtI) methodology}

This chapter gives an introduction to the use of the field Review of Outcomes to Impacts as a means of assessing progress towards the intended impacts of an intervention some years after formal project completion. The Review of Outcomes to Impacts begins with the project Terminal Evaluation and other key documents and creates a Theory of Change for the intended progression from the outcomes identified in the Terminal Evaluation towards the long-term impact objectives of the intervention.

The methodology explores the cause and effect chains of the pathway towards impacts, including the extent to which defined Intermediate States between outcomes and impacts have been achieved. This allows the assessment of progress, even in cases where the duration of the change process may be many years. By using the Review of Outcomes to Impacts method, it can be seen whether the necessary follow-up activities to an intervention have been commenced, and, if so, how far they have gone and with what results. In other words, are the intervention followup activities on track to eventually contribute towards the impacts for which the project was originally funded?

An important issue encompassed by the Review of Outcomes to Impacts methodology is the extent to which the original assumptions of the project proved accurate. For example, almost all project funding documents have the statement 'government will continue to prioritize this issue for funds and human resources'. If this does not prove to be the case, the original positive outcomes achieved may fade. The Review of Outcomes to Impacts explicitly assesses whether the assumptions have in fact held true in the longer term. In addition, the method looks at the impact drivers set in motion by the project - its champions and its support systems, which need to continue after the initial project support has gone. It assesses whether these remain sufficiently strong to keep the necessary activities and systems moving forward towards their objectives.

As shown by the example of the SEYMEMP field Review of Outcomes to Impacts, the method enables a sufficiently detailed picture to be built to give an overall assessment of progress towards impacts. It does so in a cost-effective manner, usually requiring about two person-weeks of in-country mission, most of which is spent with institutional stakeholders and with limited field-visit verification. It therefore represents an intermediate method between full impact evaluation (which requires far more resources) and desk review (which lacks the opportunity, in particular, to bring together groups of stakeholders to develop an interactive vision of what has actually happened since project closure). 
The ROtI method has been found effective in various environmental sectors and for different timescales. For example, another detailed field ROtI was conducted in Jamaica for the GEF Energy Demand Side Management project in the field of climate change. A particularly interesting aspect of this review is that it was conducted a full ten years after project completion. A brief overview of its findings is provided in Box 7.1.

\section{BOX 7.1 KEY FINDINGS OF JAMAICA DEMAND SIDE MANAGEMENT ROTI}

Ten years after project completion, the project had partially achieved its intended progress towards impact and the expected Global Environment Benefits. After a post-completion period in which it appeared that the project's contribution might fade away (apart from the market transformation for Compact Fluorescent Lightbulbs (CFLs), as a result of the privatization of the main national energy supplier, there was a return of interest focused around Government's development of an Energy Policy. This has a component sub-policy on Energy Conservation and Efficiency that explicitly refers to the DSM project as part of its antecedents. The issues around Climate Change, Energy Efficiency and Demand Side Management have also, over time, been well incorporated at all levels of the national educational system, including at University level, which is a regional facility.

Furthermore, energy efficiency approaches have recently been supported by UNDP, both in terms of specific projects in the health sector and of support to the development of the Government's Energy Policy. The Inter-American Development Bank is also providing substantial support in this area. Thus, it appears likely that the progress of Demand Side Management/Energy Efficiency will continue and even expand in future. The DSM Project has clearly made an important contribution towards these trends, although it would not be possible to say exactly how much contribution.

Whereas the earlier World Bank-GEF Post-Implementation Impact Assessment, five years after Project Completion, focused mainly on attempting to quantify the contribution of reduced GHG emissions (and reduced energy costs), the ROtI after ten years has found that a 'second wave' of results, further along the Outcomes to Impacts pathways, has become evident. These results focus in the field of enhanced knowledge and expertise concerning Energy Efficiency/Demand Side Management promoted through all levels of the education system; and in the development of a detailed and coherent Government approach towards Energy and Climate Change, embodied in a new national Energy Policy, intended to focus national approaches until the year 2030.

Overall, the field Review of Outcomes to Impacts presents a valuable addition to the range of methods available to those seeking to assess progress from project results towards long-term impacts. Furthermore, since it was specifically developed for the realm of environmental interventions (notably for global environmental activities), it does not suffer from the difficulties commonly experienced in adapting methods of poverty-focused evaluation to the environment sector. 


\section{A. Annex 1: Overall SEYMEMP Theory of Change}

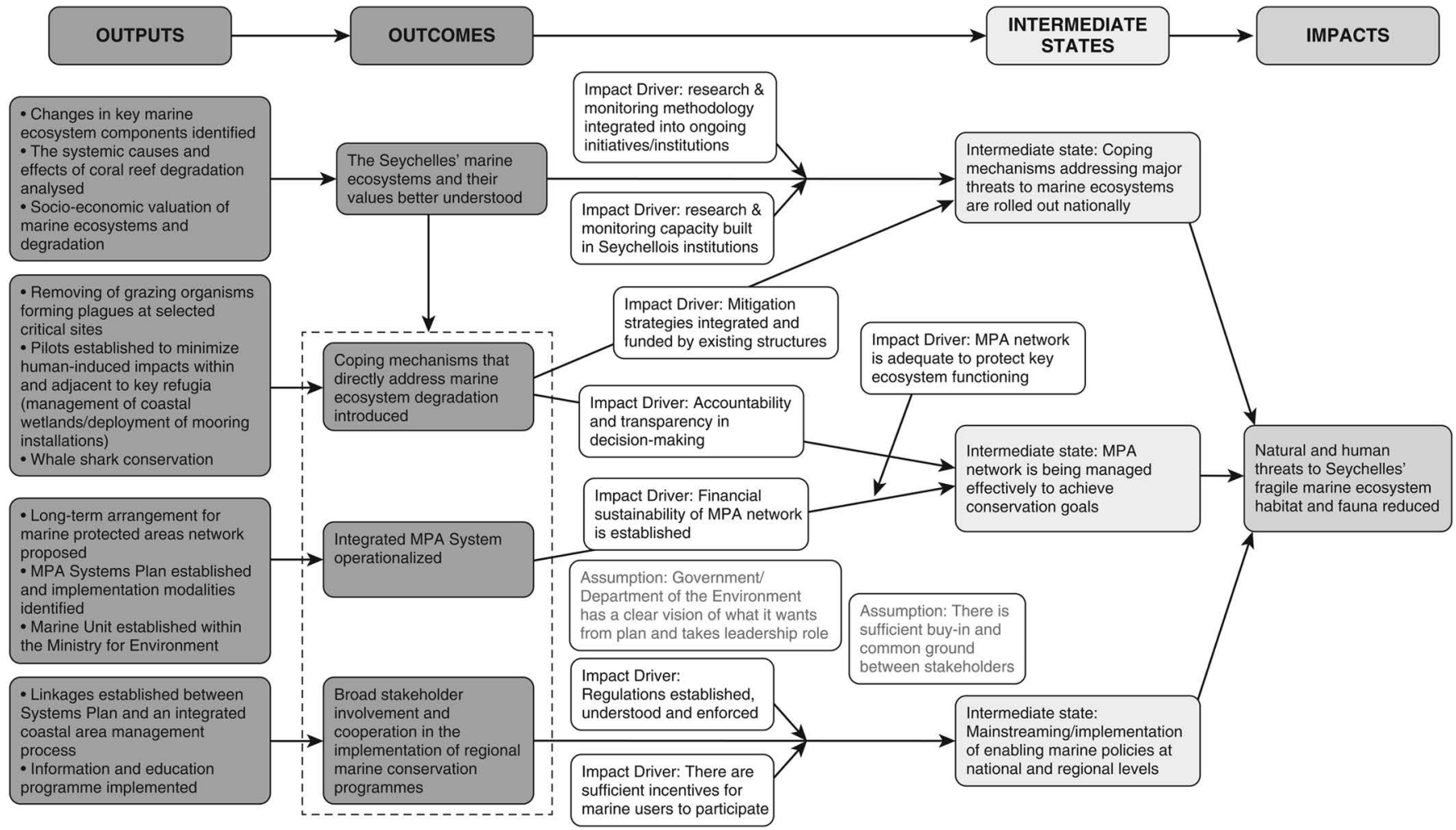

FIGURE 7.8 Overall SEYMEMP Theory of Change 


\section{Notes}

1 See, for example, Leeuw and Vaessen (2009) and 3ie (2013).

2 Further details on this work are provided in R. van den Berg and D. Todd (2011).

3 See GEF Evaluation Office (2006).

4 See GEF Evaluation Office (2009a).

5 The range of approaches and methods used by the GEF Independent Evaluation Office is described on its website: https://www.gefieo.org/knowledge-methods.

6 There is also a desk review of Outcomes to Impacts, which uses only project documents to assess the fit between project design and delivery at completion and the intended pathway towards impacts.

7 Full details of the Review of Outcomes to Impacts methodology have been provided in a handbook. See GEF Evaluation Office (2009b).

8 See GEF Evaluation Office (2009b).

9 The acronym MPA refers to the Marine Protected Area system. A similar acronym, the SCMRT-MPA, refers to an institution, the Seychelles Centre for Marine Research and Technology - Marine Parks Authority.

10 See GEF Evaluation Office (2009a).

11 In order to keep the chapter to a manageable length, only a summary of the review process is provided for this intermediate state (the full method has been outlined for Intermediate State 3).

12 See Engelhardt (2004a, 2004b).

\section{References}

Engelhardt, U., 'The status of scleractinian coral and reef associated fish communities 6 years after the 1998 mass coral bleaching event', Consultancy report by Reefcare International, Australia, 2004a.

Engelhardt, U., 'Seychelles integrated marine protected area system plan', Consultancy report by Reefcare International, Australia. 2004b.

Global Environment Facility (GEF) Evaluation Office, GEF Country Portfolio Study: Jamaica. Review of Outcomes to Impacts: Jamaica Demand Side Management Project (Volume 2), Washington, DC, 2011.

Global Environment Facility (GEF) Evaluation Office, The Role of Local Benefits in Global Environmental Programs, Washington, DC, 2006.

GEF Evaluation Office, 'Seychelles Marine Ecosystem Management Project: Review of Outcomes to Impacts', Nairobi and Washington, DC, 2009a.

GEF Evaluation Office, 'The Review of Outcomes to Impacts Handbook: Towards Enhancing the Impacts of Environmental Projects', Nairobi and Washington, DC 2009b.

International Initiative for Impact Evaluation (3IE), 2013 'Improving Lives Through Impact Evaluation: A Strategy for 3IE 2010-2013', New Delhi, India available at http:// www.3ieimpact.org/media/filer/2012/05/17/3ie_strategy_report_2010-13.pdf, last accessed September 122013.

Leeuw, F. and J. Vaessen, Impact Evaluations and Development: NONIE Guidance on Impact, , Network of Networks for Impact Evaluation, Washington, DC2009.

van den Berg, R. and D. Todd, 'The full road to impact: The experience of the Global Environment Facility fourth overall performance study', Journal of Development Effectiveness, no. 3, 2011. 